\title{
Uitval zonder diploma: Aanleiding, Kansen en Toekomstintenties
}

Citation for published version (APA):

Schurgers, S., Meng, C., \& Huijgen, T. (2019). Uitval zonder diploma: Aanleiding, Kansen en

Toekomstintenties. ROA. ROA Fact Sheets No. 007 https://doi.org/10.26481/umarof.2019007

Document status and date:

Published: $31 / 10 / 2019$

DOI:

10.26481/umarof.2019007

Document Version:

Publisher's PDF, also known as Version of record

\section{Please check the document version of this publication:}

- A submitted manuscript is the version of the article upon submission and before peer-review. There can be important differences between the submitted version and the official published version of record.

People interested in the research are advised to contact the author for the final version of the publication, or visit the DOI to the publisher's website.

- The final author version and the galley proof are versions of the publication after peer review.

- The final published version features the final layout of the paper including the volume, issue and page numbers.

Link to publication

\footnotetext{
General rights rights.

- You may freely distribute the URL identifying the publication in the public portal. please follow below link for the End User Agreement:

www.umlib.nl/taverne-license

Take down policy

If you believe that this document breaches copyright please contact us at:

repository@maastrichtuniversity.nl

providing details and we will investigate your claim.
}

Copyright and moral rights for the publications made accessible in the public portal are retained by the authors and/or other copyright owners and it is a condition of accessing publications that users recognise and abide by the legal requirements associated with these

- Users may download and print one copy of any publication from the public portal for the purpose of private study or research.

- You may not further distribute the material or use it for any profit-making activity or commercial gain

If the publication is distributed under the terms of Article $25 \mathrm{fa}$ of the Dutch Copyright Act, indicated by the "Taverne" license above, 


\title{
Maastricht University $\$$ ROA
}

\section{Uitval zonder diploma: Aanleiding, Kansen en Toekomstintenties}

\section{ROA Factsheet}

\author{
ROA-F-2019/7
}

Researchcentrum voor Onderwijs en Arbeidsmarkt | ROA Research Centre For Education and the Labour Market / ROA 


\section{Uitval zonder diploma: Aanleiding, Kansen en Toekomstintenties}

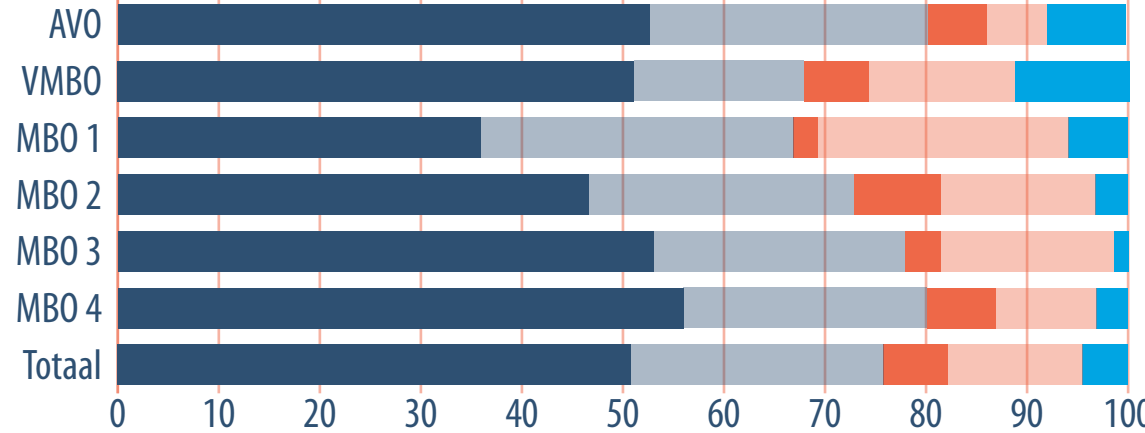

Schoolgerelateerde oorzaken (Geestelijke) gezondheidsproblemen - Persoonlijke problemen Arbeidsmarkt Anders

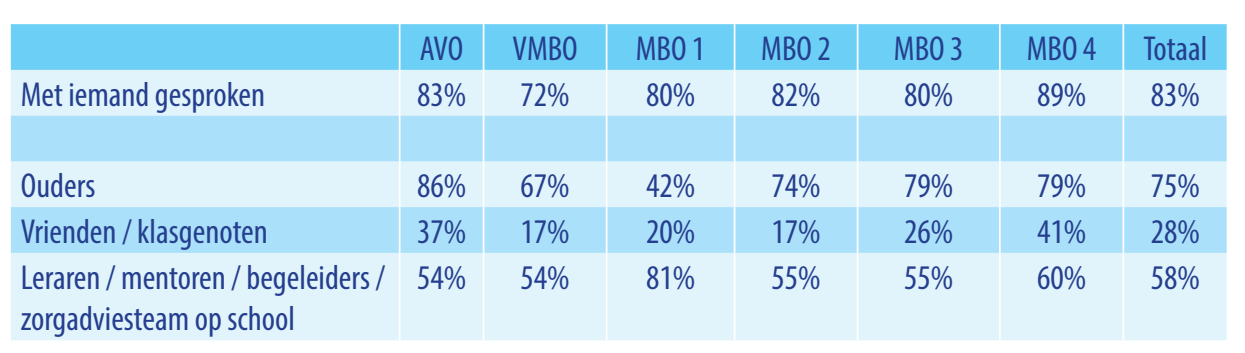

zorgadviesteam op school

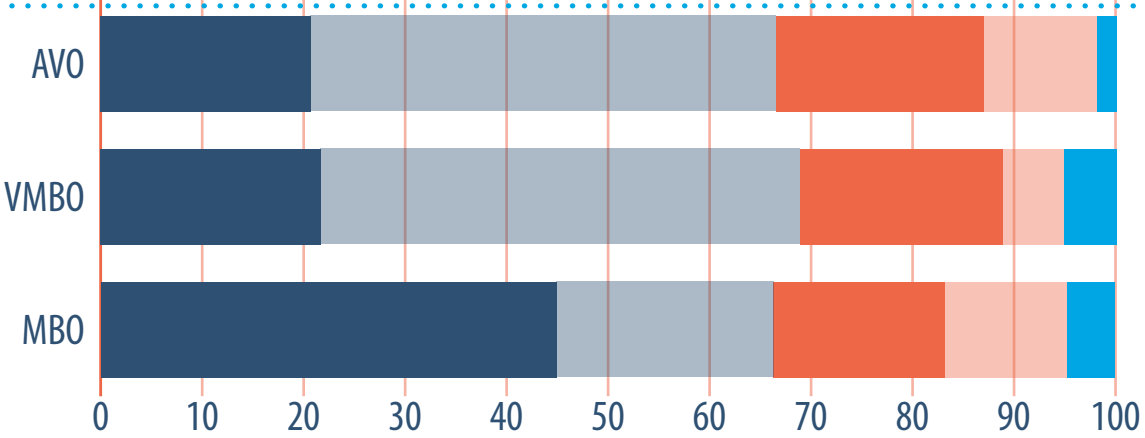

Werk Studie Combinatie werk-leren Werkloos $\square$ Anders
Belangrijkse reden om te stoppen

- Meer dan de helft van de belangrijkste redenen die aangevoerd worden om te stoppen zijn school-gerelateerd (53\%). Ook gezondheidsproblemen (28\%) en de lonkende arbeidsmarkt $(13 \%)$ worden relatief vaak genoemd.

- De belangrijkste individuele school-gerelateerde reden bij VSV-ers in het mbo is de opleiding was inhoudelijk (toch) niet wat ik wilde (15\%).

Gesprekken voorafgaand aan uitval

- Vier op de vijf jongeren geeft aan gesprekken gevoerd te hebben over het voortijdig verlaten van de opleiding.

- In drie van de vier gevallen die gesprekken gevoerd hebben, zijn dit gesprekken geweest me de ouders, bijna $60 \%$ heeft met iemand van de school gesproken.

Bezigheid op moment van enquête

De meerderheid van de VSV-ers afkomstig van het avo en vmbo is op moment van enquête weer in het onderwijs of volgt een werk / leertraject. Bij VSV-ers uit het mbo is werken de meest voorkomende activiteit op moment van enquête.

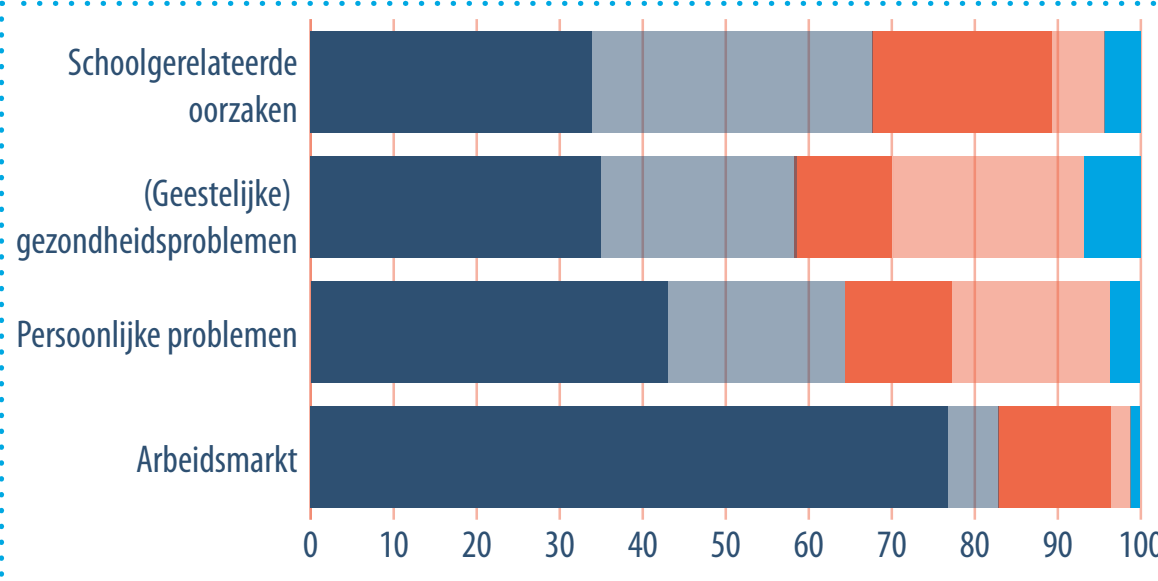

Werk Studie Combinatie werk-leren Anders Werkloos

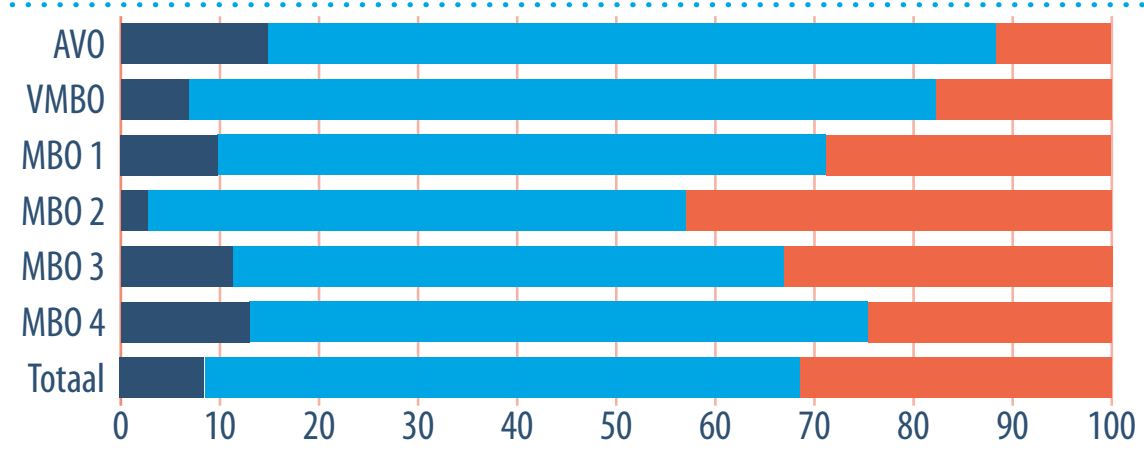

Ja en ingeschreven Ja maar onduidelijke welke/wanneer Nee

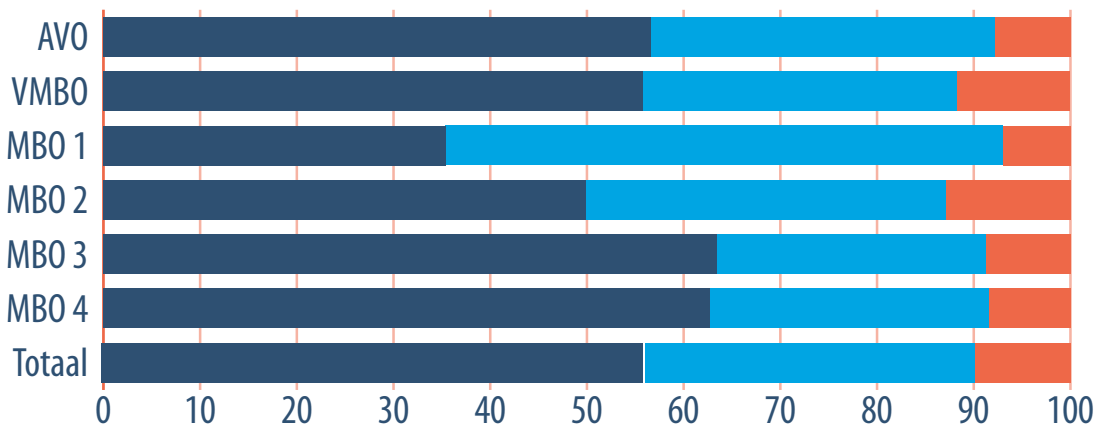

$\square$ Nee $\square$ Ja, maar ik kon destijds niet anders $\square$ Ja, dat zou ik nu niet meer doen
Bezigheid naar reden voortijdige schooluitval

- Jongeren die aangaven dat school-gerelateerde oorzaken de belangrijkste reden waren voor uitval, volgen relatief gezien het vaakst opnieuw een opleiding $(34 \%)$.

De jongeren die de school voortijdi verlaten hebben vanwege de arbeidsmarkt werken het vaakst $(77 \%)$.

- (Geestelijke) gezondheidsproblemen leiden het vaakst tot werkloosheid $(7 \%)$

Opleidingsplannen

- Zeven op de tien jongeren die op enquêtemoment geen opleiding volgen zijn van plan om op een late tijdstip wederom een opleiding te volgen. Onder de jongeren va het vmbo is dit $82 \%$ en onder de jongeren van de avo zelfs bijna $90 \%$

Spijt achteraf

- lets meer dan de helft van de jongeren heeft geen spijt van het ongediplomeerd verlaten van de opleiding

Jongeren die vanwege school- of arbeidsmarktgerelateerde redenen de opleiding voortijdig verlieten, hebben relatief het minst spijt.

- (Geestelijke) gezondheidsproblemen dan wel persoonlijke problemen leiden het vaakst tot spijt. 
Maastricht University \&

\section{Uitval zonder diploma: Aanleiding, Kansen en Toekomstintenties}

Bijlagen

Tabel B1: Achtergrondkenmerken respondenten (\%)

\begin{tabular}{|c|c|c|c|c|c|c|c|}
\hline & AVO & VMBO & MBO 1 & $\mathrm{MBO} 2$ & $\mathrm{MBO} 3$ & $\mathrm{MBO} 4$ & Totaal \\
\hline \multicolumn{8}{|l|}{ Opleidingssector } \\
\hline Algemeen & 100.0 & 86.0 & 14.4 & & & & 23.3 \\
\hline Landbouw & & 2.9 & 0.4 & 4.6 & 5.3 & 2.6 & 3.1 \\
\hline Techniek & & 4.8 & 25.6 & 33.0 & 20.1 & 26.2 & 21.4 \\
\hline Economie & & 3.2 & 36.7 & 43.7 & 47.9 & 40.9 & 33.0 \\
\hline Gezondheidszorg & & 3.1 & 22.9 & 15.9 & 15.4 & 18.0 & 13.4 \\
\hline Gedrag \& maatschappij & & & & 2.8 & 11.3 & 12.4 & 5.8 \\
\hline \multicolumn{8}{|l|}{ Leerweg } \\
\hline Theoretisch & & 65.7 & & & & & \\
\hline Gemengd & & 7.0 & & & & & \\
\hline Kaderberoepsgericht & & 4.8 & & & & & \\
\hline Basisberoepsgericht & & 22.5 & & & & & \\
\hline Leeftitid (gemiddelde) & 19.6 & 18.2 & 20.3 & 20.2 & 20.4 & 20.4 & 20.0 \\
\hline Man & 68 & 62 & 54 & 66 & 55 & 63 & 63 \\
\hline Vrouw & 32 & 38 & 46 & 34 & 45 & 37 & 37 \\
\hline \multicolumn{8}{|l|}{ Etniciteit } \\
\hline Westerse allochtoon & 17 & 7 & 0 & 5 & 8 & 12 & 9 \\
\hline Niet-westerse allochtoon & 30 & 54 & 56 & 28 & 24 & 24 & 31 \\
\hline Autochtoon & 53 & 39 & 44 & 67 & 68 & 65 & 60 \\
\hline \multicolumn{8}{|l|}{ Gezinssamenstelling } \\
\hline Tweeoudergezin & 62 & 55 & 28 & 56 & 69 & 61 & 58 \\
\hline Eenoudergezin & 20 & 23 & 44 & 30 & 20 & 25 & 26 \\
\hline Zelfstandig & 13 & 20 & 21 & 15 & 7 & 13 & 14 \\
\hline Anders & 6 & 2 & 7 & & 5 & 1 & 3 \\
\hline \multicolumn{8}{|l|}{ Taalgebruik thuis } \\
\hline (Bijna) altijd Nederlands & 64 & 49 & 47 & 58 & 73 & 70 & 63 \\
\hline Nederlands en een andere taal & 19 & 14 & 46 & 22 & 16 & 16 & 20 \\
\hline (Bijna) altijd een andere taal & 7 & 20 & 4 & 8 & 3 & 4 & 7 \\
\hline Niet van toepassing & 9 & 16 & 4 & 12 & 9 & 10 & 11 \\
\hline \multicolumn{8}{|l|}{ Opleidingsniveau ouders } \\
\hline Basisonderwijs & 1 & 4 & 13 & 0 & 3 & 2 & 2 \\
\hline $\begin{array}{l}\text { Lager beroepsonderwijs (lbo/vbo/ } \\
\text { vmbo/mavo) }\end{array}$ & 4 & 4 & 14 & 10 & 10 & 9 & 8 \\
\hline Voortgezet onderwijs (havo/vwo) & 2 & 3 & 2 & 7 & 3 & 3 & 4 \\
\hline Middelbaar beroepsonderwijs & 15 & 26 & 19 & 31 & 35 & 24 & 26 \\
\hline Hoger onderwijs & 66 & 31 & 11 & 21 & 32 & 46 & 36 \\
\hline Onbekend & 12 & 32 & 42 & 31 & 18 & 17 & 24 \\
\hline
\end{tabular}

\begin{tabular}{|c|c|c|c|c|c|c|c|c|}
\hline & & AVO & VMBO & MBO 1 & $\mathrm{MBO} 2$ & MBO3 & $\mathrm{MBO} 4$ & Totaal \\
\hline \multirow[t]{10}{*}{ School gerelateerde oorzaken } & $\begin{array}{l}\text { De opleiding was te moeilijk en/of gezakt voor het } \\
\text { eindexamen }\end{array}$ & 16.5 & 12.0 & 3.2 & 3.9 & 3.4 & 4.2 & 6.4 \\
\hline & Problemen op de leerwerkplek/stage (bijv. ontslag) & 0 & 0 & 4.5 & 4.2 & 8.0 & 3.3 & 3.5 \\
\hline & Geen stageplek kunnen vinden & 0 & 0.9 & 5.1 & 2.2 & 1.4 & 1.4 & 1.6 \\
\hline & Problemen met de leraren/schoolleiding & 3.1 & 7.1 & 4.7 & 6.3 & 8.4 & 5.2 & 5.8 \\
\hline & Problemen met andere leerlingen & 1.0 & 3.8 & 2.2 & 2.8 & 0.0 & 2.8 & 2.2 \\
\hline & Ik wilde van opleiding wisselen & 13.9 & 8.6 & 3.0 & 3.1 & 6.1 & 4.1 & 5.8 \\
\hline & De opleiding was inhoudelijk (toch) niet wat ik wilde & 5.2 & 4.6 & 5.0 & 13.3 & 9.7 & 21.7 & 12.7 \\
\hline & Ik vond het niveau van de opleiding te laag & 2.0 & 5.7 & 2.7 & 3.0 & 2.0 & 3.4 & 3.1 \\
\hline & Vanwege problemen met taal en/of rekenen & 3.4 & 5.5 & 0.0 & 1.3 & 1.0 & 0.0 & 1.5 \\
\hline & De opleiding was slecht georganiseerd & 7.7 & 2.8 & 5.4 & 6.4 & 13.0 & 10.1 & 8.1 \\
\hline Subtotaal & & 52,8 & 51 & 35,8 & 46,5 & 53 & 56,2 & 50,7 \\
\hline \multirow[t]{2}{*}{$\begin{array}{l}\text { (Geestelijke) } \\
\text { gezondheidsklachten }\end{array}$} & $\begin{array}{l}\text { Problemen met gezondheid, bijv. ziekte of } \\
\text { verslavingsproblemen }\end{array}$ & 8.5 & 4.4 & 19.1 & 11.9 & 12.7 & 9.6 & 10.6 \\
\hline & Psychische problemen & 19.2 & 12.4 & 11.8 & 14.4 & 12.2 & 14.5 & 14.4 \\
\hline Subtotaal & & 27,7 & 16,8 & 30,9 & 26,3 & 24,9 & 24,1 & 25 \\
\hline \multirow[t]{2}{*}{ Persoonlijke problemen } & $\begin{array}{l}\text { Relatieproblemen/gezinsproblemen (bijv. scheiding van } \\
\text { ouders }\end{array}$ & 3.5 & 2.7 & 0.8 & 4.8 & 3.5 & 5.5 & 4.2 \\
\hline & $\begin{array}{l}\text { School in combinatie met zorg voor kinderen en/of familie } \\
\text { was te zwaar }\end{array}$ & 2.3 & 3.7 & 1.6 & 3.8 & 0.0 & 1.2 & 2.2 \\
\hline Subtotaal & & 5,8 & 6,4 & 2,4 & 8,6 & 3,5 & 6,7 & 6,4 \\
\hline \multirow[t]{2}{*}{ Arbeidsmarkt } & Ik wilde liever gaan werken & 3.8 & 8.2 & 16.7 & 11.8 & 12.2 & 7.6 & 9.5 \\
\hline & Ik had een inkomen nodig en ben daarom gaan werken & 2.2 & 6.4 & 8.1 & 3.5 & 5.0 & 2.4 & 3.8 \\
\hline Subtotaal & & 6 & 14,6 & 24,8 & 15,3 & 17,2 & 10 & 13,3 \\
\hline \multirow[t]{2}{*}{ Anders } & Ik ging verhuizen & 3.7 & 6.5 & 5.0 & 2.9 & 1.1 & 0.4 & 2.5 \\
\hline & Anders & 4.2 & 4.8 & 1.0 & 0.3 & 0.4 & 2.7 & 2.0 \\
\hline Subtotaal & & 7,9 & 11,3 & 6 & 3,2 & 1,5 & 3,1 & 4,5 \\
\hline
\end{tabular}


Maastricht University $\$ \mathrm{ROA}$

\section{Uitval zonder diploma: Aanleiding, Kansen en Toekomstintenties}

Tabel B3: Wat houd je tegen om met een nieuwe opleiding te beginnen? (meerdere antwoorden mogelijk) (\%)

\begin{tabular}{|c|c|c|c|c|c|c|c|}
\hline & AVo & VMBO & MBO 1 & MBO2 & $\mathrm{MBO} 3$ & $\mathrm{MBO} 4$ & Totaal \\
\hline Ik weet niet welke opleidingen er zijn & 18 & 13 & 21 & 11 & 8 & 11 & 12 \\
\hline De opleiding die ik wil doen heeft geen plek meer vrij & 1 & 1 & 4 & 2 & 0 & 1 & 2 \\
\hline De opleiding die ik wil doen is te ver weg & 0 & 6 & 0 & 4 & 2 & 5 & 4 \\
\hline Ik voldoe niet an de minimale eisen om met de opleiding te beginnen & 25 & 22 & 25 & 12 & 3 & 12 & 14 \\
\hline Ik moet nog wachten omdat dit slechts op een beperkt aantal momenten kan & 4 & 8 & 12 & 3 & 6 & 9 & \\
\hline De kosten zijn te hoog & 23 & 13 & 17 & 20 & 8 & 20 & 18 \\
\hline Ik kan via mijn werk verder leren & 10 & 8 & 2 & 14 & 15 & 16 & 13 \\
\hline Ik heb geen verdere studie nodig & 4 & 9 & 1 & 9 & 7 & 8 & 7 \\
\hline Ik wil me door middel van cursussen verder ontwikkelen & 13 & 5 & 4 & 15 & 16 & 18 & 14 \\
\hline Het is niet mogelijk vanwege persoonlijke omstandigheden & 31 & 20 & 25 & 22 & 17 & 18 & 21 \\
\hline Ik heb geen zin meer in het onderwijs & 19 & 10 & 30 & 30 & 24 & 29 & 26 \\
\hline Anders, namelijk & $42 \%$ & $35 \%$ & $24 \%$ & $20 \%$ & $22 \%$ & $28 \%$ & $25 \%$ \\
\hline
\end{tabular}

Noot: Alleen respondenten die niet in het onderwijs zitten.

Tabel B4: Wat zou je kunnen stimuleren om met een nieuwe opleiding te beginnen? (meerdere antwoorden mogelijk)(\%)

\begin{tabular}{|l|r|r|r|r|r|r|r|}
\hline & AVO & VMBO & MBO 1 & MBO2 & MBO3 & MBO4 & Totaal \\
\hline Het krijgen van studiefinanciering & 41 & 38 & 15 & 26 & 19 & 33 & 29 \\
\hline Financiële steun van de gemeente & 33 & 34 & 35 & 23 & 28 & 32 & 29 \\
\hline Als ik de opleiding naast mijn huidige baan zou kunnen volgen & 24 & 16 & 22 & 25 & 30 & 36 & 27 \\
\hline Als ik op korte terminn zou kunnen beginnen & 15 & 5 & 12 & 10 & 7 & 11 & 10 \\
\hline Hulp bij de studiekeuze zodat tik weet wat voor een opleiding ik wil gaan doen & 38 & 31 & 33 & 22 & 24 & 23 & 26 \\
\hline
\end{tabular}

Hulp bij de studiekeuze zodat tik weet wat voor een opleiding ik wil gaan doen

Tabel B5: Spijt achteraf, naar belangrijkste reden voor de voortijdige uitval (\%)

\begin{tabular}{l|rrrrrr} 
& $\begin{array}{r}\text { school } \\
\text { gerelaterde } \\
\text { 0orzaken }\end{array}$ & $\begin{array}{r}\text { (geestelijke) } \\
\text { gezondheidsproblemen }\end{array}$ & $\begin{array}{r}\text { persoonlijke } \\
\text { problemen }\end{array}$ & arbeidsmarkt & anders & Total \\
\hline Nee & 60 & 45 & 34 & 65 & 63 & 56 \\
\hline Ja, dat zou ik nu niet meer doen & 12 & 6 & 6 & 15 & 3 & 10 \\
\hline Ja, maar ik kon destijds niet anders & 28 & 49 & 60 & 20 & 34 & 34 \\
& $100 \%$ & $100 \%$ & $100 \%$ & $100 \%$ & $100 \%$ & $100 \%$ \\
\hline
\end{tabular}




\section{Over de data}

1. De cijfers in dit factsheet zijn afkomstig van het onderzoek onder jongeren die in het schooljaar 2016-2017 met hun opleiding stopten en het onderwijs verlieten. Het betreft daarbij jongeren die op moment van stoppen jonger dan 23 jaar oud waren en nog geen 'arbeidsmarktkwalificatie' dat wil zeggen mbo niveau 2 of havo/vwo diploma behaald hebben.

2. Het onderzoek werd in het kader van het Schoolverlatersonderzoek door het CBS in samenwerking met het ROA uitgevoerd.

3. De enquêtes vonden plaats in het najaar van 2018 onder jongeren die in het schooljaar 2016-2017 met de opleiding stopten.

\section{Toelichtingen}

1. Deelnemers aan enquête: Jongeren die in het schooljaar 2016/17 het onderwijs hebben verlaten zonder startkwalificatie en die in het schooljaar 2017/2018 niet in het onderwijs ingeschreven staan. Op moment van enquête (schooljaar 2018/2019) kunnen de jongeren echter weer in het onderwijs ingeschreven staan.

2. Werkloze beroepsbevolking $=\%$ dat zich op de arbeidsmarkt aanbiedt (exclusief respondenten die zich als student zien) en dat niet werkzaam (=o uur) is en tegelijkertijd op zoek naar werk is.

3. Alle gepresenteerde cijfers in dit factsheet zijn gebaseerd op het gewogen databestand. Hiermee wordt er rekening gehouden met responseverschillen tussen bijvoorbeeld opleidingsniveau of geslacht.

\section{Contactpersoon}

Christoph Meng, c.meng@maastrichtuniversity.nl

Deze factsheet is tot stand gekomen als onderdeel van het Project Onderwijs-Arbeidsmarkt (POA; http://roa. sbe. maastrichtuniversity.nl/?portfolio=poa-project-onderwijsarbeidsmarkt-2), mede dankzij financiering van NRO (dossiernummer 405-17-900), UWV, S-BB en Randstad.

\section{Colofon}

(๑) Researchcentrum voor Onderwijs en Arbeidsmarkt Niets uit deze uitgave mag op enige manier worden verveelvoudigd zonder voorafgaande schriftelijke toestemming van de directeur van het ROA.

Researchcentrum voor Onderwijs en Arbeidsmarkt

Maastricht University

School of Business and Economics

secretary-roa-sbe@maastrichtuniversity.nl www.roa.nl

\section{Vormgeving}

ROA secretariaat, Maastricht

september 2019 